\title{
Обзоры. Рецензии
}

\section{Book Reviews and Common References}

DOI: $10.37892 / 2218-1393-2021-15-2-152-167$

\author{
Рецензия на коллективную монографию \\ Иоанесян Е.Р., Рябцева Н.К., Ковшова М.Л., Дронов П.С., Орлова О.С. \\ Представление эмоциональной сферы человека на материале разных язы- \\ ков. М., 2020. 244 с.
}

\section{О.А. Гулыга (Институт языкознания РАН)}

Целью монографии, как следует из названия, является исследование выразительных средств ряда языков, в основном европейских, предназначенных для отражения, кодирования, концептуализации и осмысления сферы эмоций. Данный предмет исследования имеет свою специфику. Прежде всего, область эмоций — это универсальная принадлежность внутреннего мира человека и следует ожидать, что любой язык располагает разноуровневыми, и в первую очередь лексическими, средствами для её отражения. В монографии концепты эмоций рассматриваются в тесной связи с языковой картиной мира как символической средой той или иной языковой общности. Оказывается, что хотя сфера эмоций как таковая универсальна, концептуализация эмоций в языках обладает отчётливым своеобразием и неповторимостью. Этим объясняется среди прочего и высокий уровень лингвоспецифичности данного поля лексики, и, как следствие, высокий процент лексики эмоций среди безэквивалентных лексем разных языков.

Пять частей монографии за авторством разных исследователей посвящены каждая отдельному аспекту изучения эмоций.

Часть I монографии «ТИПЫ СЕМАНТИЧЕСКИХ ПЕРЕХОДОВ, ЛЕЖАЩИХ В ОСНОВЕ НОМИНАЦИИ ЭМОЦИЙ» [Представление 2020, 5-69] (автор Е. Р. Иоанесян) представляет собой исследование семантической деривации на материале лексики эмо- 
ций. Изучение семантической деривации приобрело в настоящее время особое значение, что связано со сдвигом интереса лингвистов к обнаружению механизмов языка на фоне больших объёмов накопления и объяснения языкового материала. Термин «семантическая деривация» может означать и процесс, и результат этого процесса. Е.Р. Иоанесян пользуется также термином «семантический переход», понимаемым так же, как семантическая деривация в значении результата.

По аналогии с производностью словообразовательной при семантической производности мы имеет дело с появлением нового слова, т.е. слова с другим значением, полученного не морфологическими, а семантическими средствами. Связь разных значений слова устанавливается в рамках синхронной многозначности, а также, что важно, и между значениями слова в разные моменты его истории.

В части I системно представлены основные типы семантических переходов, лежащих в основе номинации эмоций в разных языках. Предметом исследования являются предикаты, обозначающие страх, разочарование, сожаление и раскаяние, радость и удовольствие в разных языках - русском, латинском, английском, французском, испанском, итальянском, португальском, немецком, польском.

В части ІІ «ЭМОЦИОНАЛЬНАЯ СФЕРА ЧЕЛОВЕКА: ИНТЕГРАЛЬНОЕ ПРЕДСТАВЛЕНИЕ ЭМОЦИОНАЛЬНОГО, РАЦИОНАЛЬНОГО И ЭСТЕТИЧЕСКОГО В СОСТОЯНИЯХ СОЗНАНИЯ, ЯЗЫКЕ И КОММУНИКАЦИИ» [Представление 2020, 70123] (автор Н. К. Рябцева) рассматриваются лингвистические средства, отражающие взаимодействие эмоционального, рационального и эстетического в сознании человека, в языке, речи и коммуникации. Особое внимание уделяется особенностям научной коммуникации и её метанаучной и прагмаэстетической квалификации, а также соответствующим прикладным проблемам языкознания, таким как проблемы переводоведения, преподавания иностранных языков и некоторым другим.

В части ІІІ «ПРИЛАГАТЕЛЬНОЕ ЭМОЦИОНАЛЬНОЙ ОЦЕНКИ СТРАШНЫЙ: ЗНАЧЕНИЕ И УПОТРЕБЛЕНИЕ» [Представление 2020, 124- 165] (автор М.Л. Ковшо- 
ва) исследуются семантические признаки прилагательного страшный, способы и условия их выражения.

В части IV «СОМАТИЧЕСКИЕ ИДИОМЫ, ОБОЗНАЧАЮЩИЕ ЭМОЦИИ: ЖЕСТЫ И СИМПТОМАТИЧЕСКИЕ ВЫРАЖЕНИЯ» [Представление 2020, 166-194] (автор П.С. Дронов) анализируется значение и употребление идиом с компонентамисоматизмами (волосы, глаза, ногти, когти, сердце и душа). Материалом для исследования послужили фразеологические единицы русского, сербохорватского, английского, немецкого и ирландского языков.

В части V «ЭВФЕМИЗАЦИЯ КАК РЕЧЕВАЯ СТРАТЕГИЯ СДЕРЖИВАНИЯ ЭМОЦИЙ (НА МАТЕРИАЛЕ АНГЛИЙСКИХ И РУССКИХ ЭВФЕМИЗМОВ НА ТЕМЫ СМЕРТИ И РОЖДЕНИЯ)» [Представление 2020, 195-212] (автор О.С. Орлова) рассматривается особое свойство эвфемизмов, заключающееся в семантическом перефокусировании и/или установлении отдалённых связей между объектом исходной и эвфемистической номинации, которое используется для того, чтобы смягчить эмоции адресата при затрагивании обиходно табуированных или деликатных тем. На примере эвфемизмов на темы рождения и смерти русского и английского языков показано, как метафорическое обозначение референтов, прямые номинации которых нежелательны в данной культуре, помогает снять внутреннее напряжение при личной коммуникации.

Рассмотрим материалы монографии в порядке следования частей $\mathrm{I}-\mathrm{V}$.

В главе 1 части I «Основные положения» автор Е.Р. Иоанесян устанавливает три типа семантических переходов. Каждый из них убедительно подтверждён материалом языковых примеров из индоевропейских языков.

Тип 1. Семантические переходы между компонентом прототипической ситуации эмоции и отдельным значением соответствующей лексемы.

В данном случае речь идёт о переходе элемента толкования лексемы в отдельное значение данной лексемы. Так, если взять толкование обозначения эмоции страх как 'состояния, вызванного негативной оценкой субъектом некоторой ситуации как опасной', 
можно в явном виде обнаружить переход элемента в значение. Переход представлен тем, что семантический элемент ситуации страха 'опасная ситуация' является также и отдельным значением этой номинации. Е.Р. Иоанесян приводит для примера значения английского fear в разные периоды истории английского языка: Old English 'peril', Middle English 'state of alarm or dread', Modern English 'state of fearing something'. От себя мы можем привести пример церковнославянского Тамо убоямася страха, идеже не бе страх (Пс $13,5)$, со значением 'Они испугались опасности там, где её не было', где страх это опасная ситуация, а страх как эмоция встроен в смысл глагола убояшася.

Е.Р. Иоанесян иллюстрирует переход 'эмоция, вызванная некоторой ситуацией' $\leftrightarrow$ ‘элемент данной ситуации’ на лексемах со следующими смыслами и их элементами:

А. 'Вкус' — 'получать удовольствие'; 'есть'/“пить' — 'получать удовольствие', ‘смотреть'/“слушать' - 'получать удовольствие'. Переход 'сенсорное ощущение' $\rightarrow$ ‘удовольствие’ также является переходом от компонента значения слова к его отдельному значению.

Б. ‘Плохой поступок’ - ‘стыд’, где эмоция стыда может быть вызвана рефлексией относительно собственных дурных поступков (компонент ситуации в основе эмоции).

Тип 2. Семантические переходы, базирующиеся на импликациях из прототипической ситуации эмоций.

Переходы типа 2 содержательно представлены следующим материалом.

А. ‘Арестованный, пленный’ $\rightarrow$ 'страх', 'раб' $\rightarrow$ 'страх'. Лишение свободы имеет следствием (импликацией) зависимость от чужой воли, потерю контроля над настоящим и будущим субъекта, отсюда страх.

Б. 'Вред, ущерб' — 'сожаление'.

Как нам представляется из трактовки данного типа у автора, этот тип отличается от предыдущего тем, что импликация из ситуации эмоций допускает бо́льшую свободу варьирования по сравнению с компонентом ситуации эмоции. Импликация является менее предсказуемой, одна и та же ситуация эмоции допускает разные импликации. 
Для примера мы со своей стороны можем привести французскую номинацию эмоции ennui, у которой выделяются следующие значения: 1) Глубокая печаль, страдание. 2) Трудность, затруднение, неприятность, проблема в одном из значений, ср. разг. проблемы с деньгами, у тебя будут проблемы. 3) Скука, отсутствие интереса, связанные с однообразием происходящего. 4) Тоска, депрессия, опустошённость, мир в чёрном цвете. Здесь, по-видимому, в качестве импликаций из базовой ситуации возможны переходы: ‘сильное блокирующее волю негативное переживание' (значение 1) — 'внешнее блокирующее контроль препятствие’ (значение 2) — ‘блокировка восприимчивости к окружающему из-за бедности стимулов' (значение 3) — 'подавление всех вообще эмоций, желаний, впечатлений, живости души в целом' (значение 4).

Тип 3. Семантические переходы, базирующиеся на инцидентных следствиях прототипической ситуации соответствующих эмоций.

Этот тип представляется наиболее сложным для понимания и в значительной степени базируется на языковой картине мира, в частности, на принципах разграничения нормы и отступления от нормы в культуре и языке. Инцидентными следствиями, ссылаясь на работу [Падучева 2004, 131], Е.Р. Иоанесян называет аксиомы человеческого поведения, которые могут объяснять мотивы поступков, причины состояний и отношений в контексте соответствующей культуры. В рамках типа 3 как примеры представлены переходы:

А. 'Наказание' - 'раскаяние'.

Б. 'Удовольствие' — 'желание'.

В главах $2-5$ первой части автор подробно и на самом разнообразном материале разбирает модели семантической деривации в классе предикатов, обозначающих страх, сожаление и раскаяние, разочарование, радость и удовольствие. В частности, в разделе «Симптоматические жесты» [Представление 2020, 56] вызывает интерес различие, проведённое между значением жеста как такового и жестовой идиомой. Приводится пример жеста закусить губу, который в русском остаётся жестом, т.е. мимическим движением, 
выражающим досаду и внутренний протест. Мы приведём свой пример данного жеста как движения: ««Но где же, — молвил с изумленьем/Зарецкий, — где ваш секундант?»... «Мой секундант? — сказал Евгений, — /Вот он: мой друг, monsieur Guillot», ...Зарецкий губу закусил...». Здесь Зарецкий раздосадован и оскорблён, т.к. Онегин привёл слугу в качестве секунданта, чем не только нарушил правила дуэли, но и поставил дворянина Зарецкого на одну доску с Гийо. Во французском значение жеста как движения дало переход к идиоме: (il) se mordit les lèvres de n'avoir y pensé 'он досадовал из-за того, что не подумал об этом’ (пример Е.Р. Иоанесян). Часть I, написанная Е.Р. Иоанесян, опирается на большой корпус толковых и этимологических словарей.

Актуальность исследования Е.Р. Иоанесян определяется и тем, что концептуальная схема слова представлена в нём как принадлежность языковой картины мира. В качестве комментария приведём яркую цитату из [Кибрик 2005, 46], хотя здесь речь идёт не об эмоциях, а об оценке: «...поучителен рассказ А.К. Жолковского об имени его информанта по языку сомали: «Наши занятия начались с того, что он объяснил мне, что его имя, Дункаль, значит 'ядовитое дерево', а также 'герой’. Я сказал, что не вижу этимологической связи. 'Ну, как же, — пояснил Дункаль, - убивает много’» [Жолковский 2000 , 51]. Полисемия имени Дункаль была для Жолковского непредсказуема, в то время как для носителя языка сомали объединяющий её смысл был совершенно очевиден. Конкретная полисемия конкретного слова конкретного языка, несомненно, индивидуальна, и даже, может быть, уникальна, но метонимическая стратегия расширения значения по функции денотата (в данном случае много убивать) универсальна». Как видим из рецензируемого исследования, упомянутая метонимическая стратегия предстаёт в более точном виде благодаря понятию инцидентного следствия.

Кроме того, благодаря исследованию Е.Р. Иоанесян приобретают бо́льшую прозрачность данные компаративистики. См., например, [etymonline.com]:

$$
\text { fear }(\mathrm{n}) \text { : }
$$


Middle English fere, from Old English foer 'calamity, sudden danger, peril, sudden attack', from Proto-Germanic "feraz 'danger' (source also of Old Saxon far 'ambush', Old Norse far 'harm, distress, deception', Dutch gevaar, German Gefahr 'danger'), from PIE *pēr-, a lengthened form of the verbal root "per- (3) 'to try, risk'.

Sense of 'state of being afraid, uneasiness caused by possible danger' developed by late 12c. Some Old English words for fear as we now use it were fyrhto, as a verb, ondrcedan. Meaning 'feeling of dread and reverence for God' is from c. 1400. To put the fear of God (into someone) 'intimidate, cause to cower'.

fear (v.)

Old English faeran 'to terrify, frighten', from a Proto-Germanic verbal form of the root of fear (n.). Cognates: Old Saxon faron 'to lie in wait', Middle Dutch vaeren 'to fear', Old High German faren 'to plot against', Old Norse faera 'to taunt'.

Originally transitive in English; long obsolete in this sense but somewhat revived in digital gaming via fear spells, which matches the old sense 'drive away by fear', attested early $15 \mathrm{c}$. Meaning 'feel fear' is late $14 \mathrm{c}$. Related: Feared, fearing.

Здесь любопытно восстановление старого значения глагола to fear 'напугать и прогнать, отпугнуть' в компьютерных играх. Данные диахронические переходы получают логичное обоснование в свете разобранных Е.Р. Иоанесян переходов страх, бояться, пугать, быстро двигаться и прятаться.

Часть II [Представление 2020, 70-123] (автор Н.К. Рябцева) коллективной моноГрафИИ «ЭМОЦИОНАЛЬНАЯ СФЕРА ЧЕЛОВЕКА: ИНТЕГРАЛЬНОЕ ПРЕДСТАВЛЕНИЕ ЭМОЦИОНАЛЬНОГО, РАЦИОНАЛЬНОГО И ЭСТЕТИЧЕСКОГО В СОСТОЯНИЯХ СОЗНАНИЯ, ЯЗЫКЕ И КОММУНИКАЦИИ» разделена на четыре главы: 1. Интегральное представление эмоционального, рационального и эстетического в состояниях сознания, речи и коммуникации; 2. Интеграция рационального, эмоционального и эстетического в современной научной коммуникации; 3. Эмоциональный интеллект: количественное и качественное соотношение эмоционального и рационального в состояниях 
сознания. Лингвистический аспект; 4. Синкретизм эмоционального, рационального и эстетического в современной научной коммуникации.

Автор ставит своей целью интегральное представление взаимодействия эмоционального, рационального и эстетического в сознании, языке и коммуникации с особым вниманием к специфике научной коммуникации. Основные положения части II можно сформулировать следующим образом.

А. Исследования сознания и мозга учитывают важную роль эмоций в когнитивных процессах и состояниях. Часто эмоции лежат в основе таких рациональных явлений, как выбор, принятие решения, фокусирование внимания и других. Иногда легко бывает обнаружить корреляцию эпистемического состояния и эмоции. Так, Н.К. Рябцева приводит пример знания/неполного знания/незнания и сопровождающих эти состояния эмоций: «Состояние «не знаю», помимо собственно рационального компонента, подразумевает целый спектр психологических и эмоциональных состояний и явлений: неуверенность, сомнение, растерянность, волнение, колебания, стресс, паника и т.п., т.е. эмоциональное переживание незнания и, тем самым, его связь с эмоциями.

Знание, напротив, внушает уверенность, эмоциональную стабильность, уравновешенность и даже повышенную активность» [Представление 2020, 72].

Б. Лексика, грамматика и фразеология, отражающие зафиксированные в языке представления о соотношении эмоционального и рационального, отличаются многообразием и прямо или косвенно связывают внутренний мир с его внешними проявлениями в поведении, речи, внешнем виде, с выражением лица и глаз, с настроением, характером, манерами [Представление 2020, 76].

В. Для научной речи характерны особые свойства синкретичного отражения эмоционального и рационального: 1) метакогнитивность — связь с рефлексией субъекта речи над процессом изложения своих мыслей (ср. «We can support this idea by the fact that $\mathrm{P} »)$; 2) риторичность - связь с порядком изложения (ср. «Let us (now) check this conclusion»); 3) аргументативность - связь с инферентными компонентами научного текста; 4) поле- 
мичность; 5) фокусирование и привлечение внимания — выделение главного, нового, актуального.

Г. В научной коммуникации наиболее ярким экспрессивно маркированным средством выступают интенсификаторы, или лексические функции Magn, относящиеся к широкому кругу лексики (соответствующие коллокации, см. [Представление 2020, 80-81]).

Е. Новые научные термины и названия научных текстов на русском и на английском языках показывают, что в названиях научных статей все чаще встречаются креативные стилистические приемы - игра слов, иронические или шутливые выражения, неожиданные цитаты, прецедентные тексты, метафорическое переосмысление понятий, а также использование более тонких стилистических и эстетических приемов, делающих научный заголовок выразительным, запоминающимся, неординарным (автор употребляет термин «аттрактивный» [Представление 2020, 91]). Эстетический компонент в современной научной коммуникации обеспечивает эстетически окрашенное активное воздействие на адресата. Происходит синтез научного и художественного языка: их сближение и взаимообогащение, обеспечивается динамическое взаимодействие рационального и эмоционального интеллекта.

Часть ІІІ «ПРИЛАГАТЕЛЬНОЕ ЭМОЦИОНАЛЬНОЙ ОЦЕНКИ СТРАШНЫЙ: ЗНАЧЕНИЕ И УПОТРЕБЛЕНИЕ» [Представление 2020, 124-165] (автор М.Л. Ковшова) представляет собой многоаспектное исследование указанной в заголовке лексемы. Лексема страшный получает разностороннюю квалификацию с точки зрения составляющих ее семантических признаков - эмоционального, интеллектуального и эстетического. Базовый смысл слова страшный основан на эмоциональной оценке, из которой выводятся остальные значения.

Эмоция страха, как уже было видно из концептуальной схемы слова страх, разобранной в части I, является ярким чувством, которое легко отрефлексировать и вряд ли можно спутать с чем-нибудь другим. У лексемы страх есть параметрические замены, выражающие градуируемость, например, боязнь, опасение, испуг, тревога, ужас, паника. 
Яркость эмоции страха подтверждается, в частности, особенностями сочетаемости лексемы страх, например, в НКРЯ словосочетание лёгкая грусть представлено 65-ю примерами, а лёгкий страх - 14-ю. Кроме того, словосочетание смутное чувство вины означает, что чувство вины слабо осознаётся, тогда как смутное чувство стра-

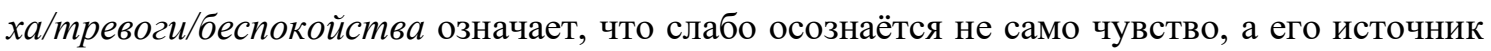
или причина.

Что касается прилагательного страшный, его негативно-оценочные значения М.Л. Ковшова разделяет на следующе группы: 1) эмоциональная оценка; 2) интеллектуальная оценка; 3) эстетическая оценка; 4) вспомогательное значение квалификатора, интенсификатора и модификатора других признаков.

Приведём трактовку каждой из групп автором: 1) Страшный — 'то, что вызывает негативную эмоциональную реакцию, страшит своими внешними качествами, воспринимаемыми сенсорно (зрением, реже - слухом)'. Эмоциональная оценка образуется в результате того, что телесно (сенсорно) воспринимаемые впечатления интерпретируются как симптомы эмоциональных переживаний [Представление 2020, 127-128], например, страшная рана. 2) Страшный - 'то, что вызывает негативную эмоциональную реакцию, страшит своими внутренними свойствами, которые подвергаются мысленному осознанию, интеллектуальной интерпретации' [Представление 2020, 128], например, страшные цифры. 3) Страшныц - 'то, что вызывает негативную эмоциональную реакцию, страшит своими внешними качествами, воспринимаемыми сенсорно (зрением, редко - слухом), не отвечающими нормативному эстетическому идеалу (индивидуальному или коллективному)' [Представление 2020, 129], например, страшна как ведьма. 4) Квалификация, интенсификация и модификация других признаков и проявлений [Представление 2020, 132], например, страшный грохот/крик.

В связи с описанием лексемы страшный в работе М.Л. Ковшовой также подробно разработаны следующие темы: 
А. Страшное как основание для сенсорной и ментальной визуализации, т.е. зримость, представимость страшного. «В семантике прилагательного страшный синтезируются критерии физического и духовного, ментального восприятия, и в этом случае зрительный способ восприятия - внутренним взором - также остается основным» [Представление 2020, 136]. Б. Особенности употребления и сочетаемости прилагательного страшный в контекстах утверждения, отрицания, предпочтения, градуируемость данного признака. В. Поведение субстантивированного варианта страшное, прилагательное страшный в разных синтаксических позициях (субъект, предикат, атрибут). Г. Обоснование, аргументация для характеристики объекта как страшного. Д. Функция прилагательного страшный в дейктической и иллокутивной сфере. Данное прилагательное используется в различных типах речевых актов - оскорблении, угрозе, предупреждении, совете, прогнозе и т.п.

Что касается дейксиса, на основании исследования М.Л. Ковшовой можно предложить следующий комментарий. Опора прилагательного страшный на зрительные данные приводит к необходимости ввести фигуру наблюдателя и признак наблюдаемости в толкование. Как известно, наблюдатель несовместим с говорящим. Так, естественно выглядят Tbl/oн страшный, вы/они страшные, чего нельзя сказать о 'Я страшный, ?'мbl страшные. Пример А он, ехидно ульбаясь, спросил: - Я, наверное, тебя жутко напугал, я такой страшный. (Сати Спивакова. Не всё (2002)) [Представление 2020, 148] нужно истолковать как взгляд говорящего на самого себя с позиции слушающего, что подтверждается присутствием наверное. Без этого показателя достоверности высказывание было бы аномальным.

М.Л. Ковшова детально исследует также синтактику лексемы страшный. Субъектом эмоциональной оценки страшный является одушевленное лицо (человек, субъект речи); объектами основных оценок — эмоциональной и эмоционально-интеллектуальной оценки - могут быть: явления, события, ситуации, действия, процессы, поступки; человек, его лицо, части тела, внешние качества и внутренние свойства, его гендерные, соци- 
альные, культурные, национальные роли; продукты ментальной и психической деятельности человека - сон, мысль, мечта, чувство; произведения речевой деятельности человека - слово, разговор и др.; результаты и орудия профессиональной и интеллектуальной деятельности человека — агрегат, пистолет, теория, цифры, книга, фильм; окружающий человека мир - природный, социальный, космос; артефакты, созданные природой, человеком, ландшафт и его части - пропасть, дорога, яма, камень, памятник; ирреальные сущности - ведьма, черт, демон, привидение; абстрактные категории - время, пространство, панорама, число [Представление 2020, 151-152).

Как видно из нашего обзора и комментариев, трактовка значения и употребления прилагательного страшный в работе М.Л. Ковшовой является примером многоуровневого, многоаспектного, основанного на обширном материале подхода к описанию фрагмента языковой картины эмоций.

Часть IV коллективной монографии «СОМАТИЧЕСКИЕ ИДИОМЫ, ОБОЗНАЧАЮЩИЕ ЭМОЦИИ: ЖЕСТЫ И СИМПТОМАТИЧЕСКИЕ ВЫРАЖЕНИЯ» [Представление 2020, 166-194] (автор П.С. Дронов) содержит исследование идиом с компонентами-соматизмами. Условная универсальность соматических реакций выражается в наличии параллельных, внешне похожих фразеологизмов в разных языках, однако интерпретация телесных проявлений чаще всего лингвоспецифична. Многие идиомы могут быть интуитивно понятны носителю одного языка, но малопонятны и загадочны для говорящего на другом языке. В данном разделе монографии рассматриваются форма, значение и особенности употребления идиом с компонентами волосы, глаза, когти в славянских (на материале русского и сербохорватского), германских (на материале английского и немецкого) и кельтских (на материале ирландского) языках. Материалом служат лексикографические источники и корпуса текстов.

У идиом с компонентом волосы эмоции концептуализируются в метафорах, отражающих движение волос под действием отрицательных эмоций (волосы дыбом, волосы зашевелились om ужаса, his hair stood on end и т.П.). В частности, автор пишет [Представ- 
ление 2020, 168]: «Семантические роли вышеперечисленных идиом способствуют конверсии и каузации: экспериенцер одновременно может восприниматься как пациенс, которого агенс «заставляет» испытывать те или иные отрицательные эмоции. Конверсивные преобразования, как правило, являются аналитическими: заставить волосы встать дыбом, to make one's hair stand on end, jmdm. die Haare zu Berge stehen lassen». Мы бы предложили здесь следующее уточнение.

В каузативной конструкции волосы не являются экспериенцером/пациенсом. Экспериенцер - это человек. Компонент волосы является фокусным, главным для идиом, с ним связана гиперроль актора [Кибрик 2005, 146], объединяющая пациенс переходного глагола и единственный актант непереходного. Что касается экспериенцера, то он принимает семантическую роль посессора волос и оформляется по синтаксическим правилам соответствующего языка, в русском мои волосыly меня волосы стали дыбом/замевелились.

В работе П.С. Дронова представляется ценным различение жеста и симптоматического движения. Различие между ними состоит в большей контролируемости, осознанности в случае жеста и спонтанности, автоматизме в случае симптоматического движения. Так, глаза могут вылезти из орбит (это движение, не жест) при физическом напряжении, страдании, страхе и удивлении [Представление 2020, 175] непроизвольным образом и независимо от воли человека.

В целом, исследование П.С. Дронова служит подробным и содержательным подтверждением особенностей метафор в языке эмоций. Жесты и симптоматические движения служат средством экстериоризации внутреннего мира, эмоций и вообще психики человека, которые исходно не воспринимаются извне. Сам выбор соматизмов показывает, что части тела как будто отделяются от своего хозяина, живут своей жизнью: волосы встают дыбом или шевелятся, некто показывает или выпускает когти, глаза вылезают из орбит. Возможно, такие метафоры отражают представление о том, что материализованную эмоцию легче распознать и, если нужно, преодолеть. 
Внутренний мир человека трактуется по аналогии с материальным миром, поэтому часто лексика эмоций воспроизводит физическую лексику в метафорическом смысле. Данную особенность П.С. Дронов анализирует в гл. 4, где речь идёт о метафорах греть/вымотать/отвести душу, плюнуть в душу, портить кровь, выйти из себя, сидеть в печёнках и подобных.

Часть V [Представление 2020, 195-212], автор О.С. Орлова, «ЭВФЕМИЗАЦИЯ КАК РЕЧЕВАЯ СТРАТЕГИЯ СДЕРЖИВАНИЯ ЭМОЦИЙ (НА МАТЕРИАЛЕ АНГЛИЙСКИХ И РУССКИХ ЭВФЕМИЗМОВ НА ТЕМЫ СМЕРТИ И РОЖДЕНИЯ)». В этой части коллективной монографии автор исследует природу, сферу употребления, типичные темы, мотивы, причины и следствия употребления эвфемизмов. Эвфемизмы представляют собой слова и выражения, которые можно охарактеризовать как разновидность косвенной номинации. Они способны смягчать высказывание, маскируя социально чувствительные для данной культуры темы. О.С. Орлова приводит список таких тем [Представление 2020, 198-199]: «...тема здоровья, беременности и рождения, смерти и похорон, вопросы, касающиеся взаимоотношений между людьми, интимных отношений и брака, анатомии и физиологии человека, внешности, характера, возраста, умственных способностей и уровня образования, (не)профессионализма, благосостояния, ... темы религии, идеологии, политики, войн и международных конфликтов, экологической обстановки, половой, расовой и национально-культурной принадлежности, вопросы, связанные со сферой бизнеса, экономики и финансов, а также с законодательной и правовой сферой».

Благодаря употреблению эвфемизмов, как убедительно показывает автор, происходит замена прямой номинации табуированного или полутабуированного в данной культуре объекта его завуалированной, размытой номинацией. В результате отрицательные ассоциации, оценочность, вызывающая сильные чувства, нивелируются. Такая коммуникативная тактика нейтрализует силу реакции адресата и сдерживает отрицательные эмоции. 
О.С. Орлова, в частности, приводит лексико-семантическую классификацию эвфемизмов на тему смерти [Представление 2020, 202]. Это косвенные наименования самого факта смерти, её причин, насильственной смерти, глаголов со значением смерти и умирания, убийства и самоубийства, убийцы, умирающего и умершего, гроба и могилы и т.д. С точки зрения языковой техники в основе большинства любых эвфемизмов лежит метафора, когнитивная или образная. Автор также в деталях рассматривает приёмы эвфемизации темы рождения и болезненную тему смерти ребёнка в утробе матери. Автор приходит к выводу, что эвфемизмы как коммуникативная практика освобождают общение от сильных негативных эмоций, что очевидным образом способствует успешности самой коммуникации. Исследование основано на материале русского и английского языков.

В качестве небольшого замечания укажем на желательность предметного указателя, указателя лексем и идиом по языкам, что могло бы очевидным образом упростить навигацию по книге. Наша рецензия частично содержит такую информацию, но её явно недостаточно. В заключение подчеркнём, что рецензируемая коллективная монография представляет собой исследование высокого уровня, охватывающее несколько областей лексической семантики языковой картины эмоций - семантические переходы и семантическую деривацию в синхронии и диахронии, концептуальную метафору, концептуальную схему лексем, варьирование плана содержания в зависимости от контекста, выдвижение на первый план того или иного компонента смысла, экстериоризацию психических процессов, языковую технику регулирования эмоций под влиянием культурного кода.

\section{Литература}

Жолковский А.К. Мемуарные виньетки и другие non-fictions. СПб.: Журнал «Звезда», 2000.

Кибрик А. Е. Константы и переменные языка. СПб.: Алетейя, 2005. 
Падучева Е. В. Динамические модели в семантике лексики. М.: Языки славянской культуры, 2004.

Представление эмоциональной сферы человека на материале разных языков. Иоанесян Е.Р., Рябцева Н.К., Ковшова М.Л., Дронов П.С., Орлова О.С. М.: Институт языкознания, 2020.

Book Review. E.R. Ioanesyan, N.K. Ryabtseva, M.L. Kovshova, P.S. Dronov, O.S. Orlova. Predstavlenie emotsional'noy sfery cheloveka na materiale raznykh yazykov ('Human emotions domain as exemplified in a variety of languages'). Moscow: Institute of linguistics, 2020. 244 p.

O.A. Gulyga (Institute of Linguistics, Russian Academy of Sciences) 